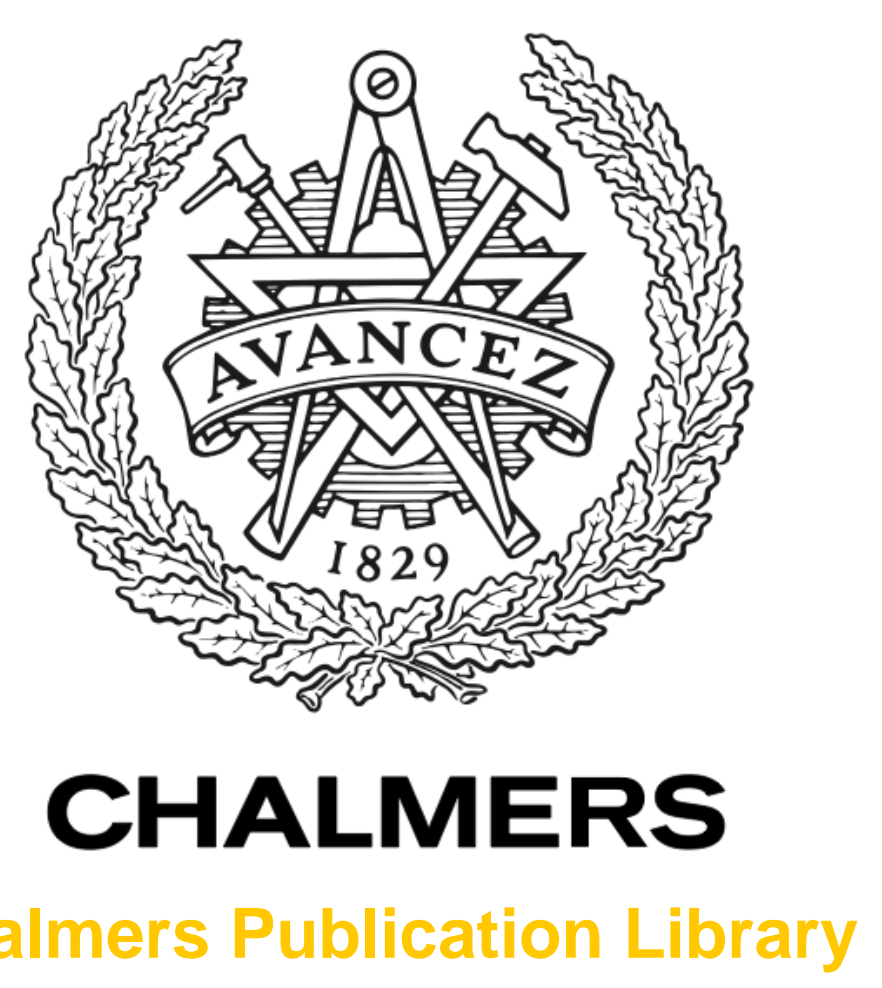

Chalmers Publication Library

\title{
Graduate students' genre knowledge and perceived disciplinary practices: Creating a research space across disciplines
}

This document has been downloaded from Chalmers Publication Library (CPL). It is the author's version of a work that was accepted for publication in:

English for specific purposes (ISSN: 0889-4906)

Citation for the published paper:

Kuteeva, M. ; Negretti, R. (2016) "Graduate students' genre knowledge and perceived disciplinary practices: Creating a research space across disciplines". English for specific purposes, vol. 41 pp. 36-49.

http://dx.doi.org/10.1016/j.esp.2015.08.004

Downloaded from: http://publications.lib.chalmers.se/publication/239865

Notice: Changes introduced as a result of publishing processes such as copy-editing and formatting may not be reflected in this document. For a definitive version of this work, please refer to the published source. Please note that access to the published version might require a subscription. 


\title{
Graduate students' genre knowledge and perceived disciplinary practices: Creating a research space across disciplines
}

\author{
Maria Kuteeva*, Raffaella Negretti \\ * Corresponding author. Tel.: +46 (0)8161230. \\ Centre for Academic English, Department of English, Stockholm University, SE-10691, Sweden \\ E-mail address: maria.kuteeva@english.su.se (M. Kuteeva).
}

\begin{abstract}
Disciplinary differences in academic writing have been addressed in applied linguistics from multiple perspectives. This article focuses on the rhetorical strategies used by multilingual graduate students from the sciences, the social sciences, and the humanities to create a research space in academic introductions. Adopting an in-depth qualitative approach, we draw on three data sources: graduate learners' analyses of model texts, their reflections on their own writing strategies, and a textual analysis of their introductions, to better understand how genre knowledge is connected to perceived disciplinary practices. Our findings indicate that the students' formal and rhetorical knowledge of genre is linked to their perception of knowledge-making practices in their respective disciplines. We discuss pedagogical implications for EAP professionals working with students from different disciplines in multilingual contexts.
\end{abstract}

\section{Keywords:}

genre knowledge, disciplinary discourse, knowledge-making practices, multilingual graduate students, academic introductions

\footnotetext{
Authors' bio

Maria Kuteeva is Professor at the Department of English, Stockholm University, and Director of the Centre for Academic English. Her research interests include EAP/ESP and multilingualism in academic settings. She has published on different aspects of academic and professional uses of English in Applied Linguistics, English for Specific Purposes, Higher Education, Journal of Multilingual and Multicultural Development, Journal of Second Language Writing, and other journals.
}

Raffaella Negretti is Senior Lecturer at Chalmers University of Technology and formerly Assistant Professor at the Department of English, Stockholm University. Her research focuses on metacognition and self-regulation in academic writing and has appeared or is forthcoming in Language Learning and Technology, Journal of Second Language Writing, Written Communication, Multilingua, and other outlets. 


\section{Introduction}

Disciplinary differences and their impact on academic writing have been addressed in applied linguistics and educational research from multiple perspectives. Most of this research has focused on the writing produced by L1 writers and professional researchers working in universities located in English-speaking countries. For example, in the 1980s Becher conducted several ethnographic studies of academics working across different disciplines and showed how their knowledge-making practices influenced their disciplinary discourses (Becher, 1987, 1989; Becher and Trowler, 2001). Some years later, Bernstein (1999) classified academic disciplines and their discourses in relation to the type of knowledge structures they represent.

Becher's and Bernstein's ideas have been further developed in applied linguistics, in relation to disciplinary discourses and genres. In the field of English for Specific Purposes, Hyland's (2000) corpus study of research articles across disciplines referred to Becher and Trowler (2001) to account for the differences found in the lexis and syntactic forms. Hyland's studies (e.g. 2000, 2005) have described differences in the quantitative distributions of lexical items and structural elements from one discipline to another, supplementing the findings of corpus analysis with interviews with writers working in the examined disciplinary fields. Other studies of disciplinary discourses in ESP have been largely corpus-based and focused on specific genres and move structures (e.g. Kuteeva \& McGrath, 2015; Huckin, 2001; Lin \& Evans, 2012; Yang and Allison, 2004) or syntactic and lexical features (e.g. Hewings \& Hewings, 2001; Hyland 1999, 2008; McGrath \& Kuteeva, 2012). At the same time, Systemic Functional Linguistics (e.g. Christie \& Maton, 2011; Martin et al., 2010; Martin, 2011; Hood, 2011) has been developing Bernstein's (1999) ideas of disciplinary knowledge structures in relation to the study of academic discourses. For example, Hood (2011) has shown how writers in different disciplines engage with knowers and knowledge in introductions to research articles. The above-mentioned research has offered some interesting insights into disciplinary differences in professional academic writing. Less attention has been paid to the impact of the discipline on L2 writing by graduate students (e.g. Hyland 2004b). It is therefore worthwhile to conduct further research into students' genre knowledge in connection with disciplinary knowledge-making practices. In this article we focus on the rhetorical strategies used by graduate students from different disciplines to create a research space in academic introductions. Adopting an in-depth qualitative approach, we draw on three data sources: graduate learners' analyses of model texts, their reflections on their own writing strategies, and a textual analysis of their texts, to better understand how genre knowledge overlaps with the ability to construct knowledge for different communities of discourse (Tardy, 2009). We address the following research questions: How do graduate students from different disciplines use their genre knowledge to create a research space? How are their rhetorical and linguistic strategies connected to perceived disciplinary knowledge-making practices?

\section{Theoretical framework}

\subsection{Knowledge-making practices}

Each discipline has its own goals and assumptions as to what constitutes knowledge (ontology) and how this knowledge is obtained (epistemology). In this article, we broadly refer to these as knowledge-making practices, which reflect the nature of the discipline and what it means to construct knowledge. As outlined in Section 1, the significance of disciplinary differences has been a recurring theme in educational and linguistic research for over twenty years. Becher 
(1989) classified disciplines according to four major categories: 'pure hard', 'pure soft', 'applied hard' and 'applied soft', depending on their epistemological characteristics. This classification has been widely used in research on disciplinary discourses (e.g. Hyland, 2000, 2005). The link between epistemology and academic discourse has also been explored by Bernstein (1999). Bernstein (1999) explains disciplinary differences through epistemological factors in connection to different kinds of knowledge structures. At one end of the continuum lie hierarchical knowledge structures, which attempt 'to create very general propositions and theories, which integrate knowledge at lower levels' (Bernstein 1999, p. 162) and are typical of the natural sciences, in which knowledge rests upon the same foundation and is accumulated through empirical enquiry. At the other end, there are horizontal knowledge structures, such as the humanities, in which knowledge is built through interpretation and through multiple interpretations of the same phenomena and artefacts. Wignell (2007) proposed a view of the social sciences as 'warring triangles', in the sense that these disciplines often model themselves on sciences but with different theoretical foundations; some theories may become dominant and marginalise others, but a single theory seldom takes over the whole discipline. For example, linguistics is seen as one such discipline (see Figure 1).

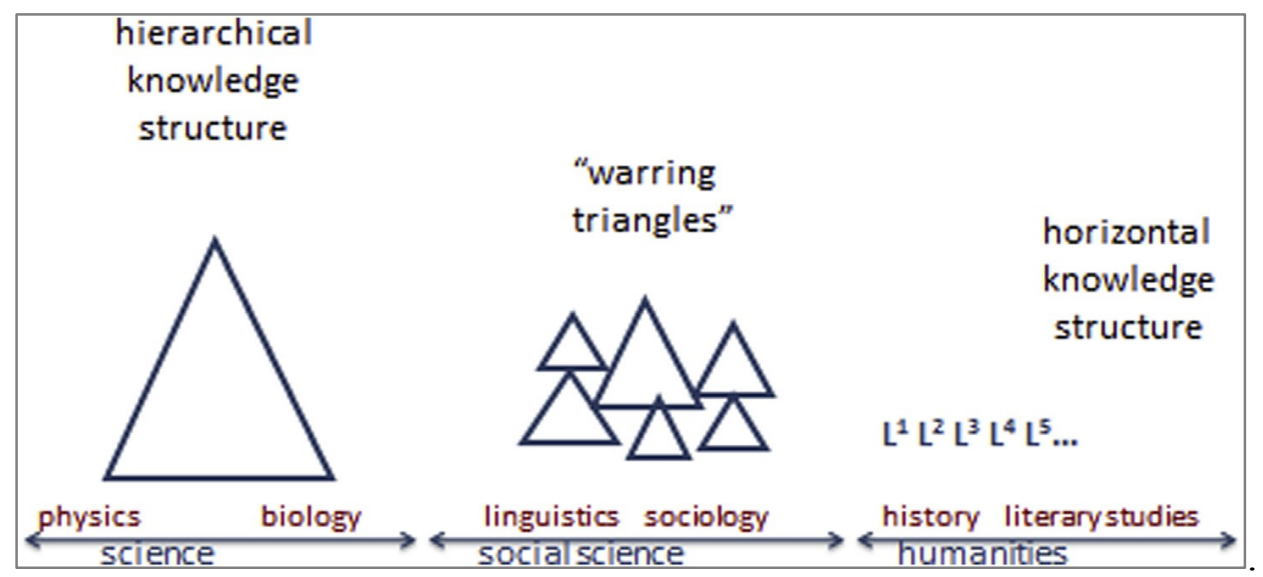

Fig.1: Knowledge structures across disciplines. Adapted from Martin (2011, pp. 42-43)

However, over the last decades, the boundaries between disciplines have become increasingly blurred. For example, theories from disciplines such as Sociology and Philosophy have been adapted to the study of literature. Trowler (2014) offers an excellent account of the "troubled" nature of disciplines in contemporary academia. He challenges the "hard" versus "soft" sciences dichotomy and argues that disciplines are context-dependent in different parts of the world. For example, the research and teaching of Sociology at a German university is not the same as the similar kinds of activities at an American university, although there will be resemblances between the two. Trowler's arguments are relevant to the teaching of academic writing in English, which should be viewed as context-situated. The following section will show how disciplinary differences are manifested in academic genres.

\subsection{Genres as reflections of disciplinary epistemologies}

Over the last decades, genre has evolved from being seen as a text type to being perceived as "a multifaceted construct characterized by a range of features that include social actions, communities of practice, power relations, texts, and the interactions among texts" (Flowerdew, 
2011, p. 120). The rhetorical structure of academic genres, and the research article (RA) in particular, has been researched extensively. Inspired by Swales' CaRS model ('Create-aResearch-Space', Swales 1981, 1990) and general description of the RA as an academic genre (Swales, 1990, pp. 110-174), a great deal of this research has dealt with the analysis of rhetorical moves in the main sections of the empirical research article, most notably the Introduction (e.g. Ozturk 2007; Samraj 2002).

Introductions to RAs play a key role in demonstrating disciplinary epistemology (cf. Swales 2004 on methods). Using an SFL approach inspired by Bernstein's concepts of hierarchical and horizontal knowledge structures, Hood (2011) has shown how academic writers across different disciplines, including the sciences, social sciences, and humanities, engage with knowers and knowledge in introductions to research articles and how they legitimate their research from a linguistic perspective. Previous research in ESP (e.g. Samraj, 2002; Ozturk, 2007; Shaw, 1998) also points towards disciplinary differences. Introductions to empirical RAs in the natural and social sciences largely follow the CaRS model (Swales, 1990): Move 1: Establishing territory; Move 2: Establishing a niche; Move 3: Occupying the niche. However, there are certain structural differences across disciplines, as well as between related disciplines (e.g. Conservation Biology and Wildlife Behaviour in Samraj, 2002), and even between sub-fields of a single discipline (e.g. applied linguistics in Ozturk, 2007). Shaw (1998) argues that literary-critical introductions are "either more direct than those of hard-science writing, and hence like those of novels, or more indirect and hence like those of sermons or belle-lettristic essays" (p. 8). Drawing on the work by Bondi (2007), Swales and Feak (2012) point out that in the humanities RAs, introductions often start with a specific event (e.g. history) or a vignette (a poem or a work of art) and proceed to discuss the topic in increasingly broad terms.

The research article plays a key function at the "centre of a web of academic genres" (Swales, 1990, p. 177). It serves to "sensitize students to rhetorical effects, and to the rhetorical structures that tend to recur in genre-specific texts" (Swales, 1990, p. 213). Overall, introductions to research articles and proposals will usually consist of "attempts to establish research territory via a review of literature" (Feak \& Swales, 2011, p. 3). There are similarities between introductions to RAs, dissertations, and research proposals in the sense that they all tend to follow the CaRS model to some extent (Feak and Swales, 2011, pp. 3, 101, 111). Therefore, this study focuses on how graduate students create a research space in their introductions. The following section will review previous research on students' genre knowledge.

\subsection{Genre knowledge}

The concept of genre has been fundamental in the study of L2 writing in English for Specific Purposes (Johns, 2002; Hyland, 2004a; Swales, 1990; Swales, 2004; Swales \& Feak, 2004; Tardy, 2009). Students in different parts of the world need to learn the discursive practices of their discipline and to develop a knowledge of genres and their communicative purposes, the sociocultural contexts in which they operate, and the cultural values they embed (Johns, 1997). Tardy's model of genre knowledge is based on her research into the genre learning of multilingual writers using English as an academic lingua franca, whom she views as "typical writers" (p. 5) of today. Drawing on previous research on disciplinary writing (e.g. Beaufort, 1999, 2004; Johns, 1997; Swales, 1990), her model of genre knowledge incorporates four different dimensions (Tardy 2009, pp. 20-22): 
- Formal knowledge: the structural elements of genre, including discourse and lexicogrammatical conventions, its structural moves, the modes and media of communicating the genre, and the associated linguistic code.

- Process knowledge: the procedural practices, including the composing processes for written genres, their dissemination and reception by the audience, and any associated genre networks.

- Rhetorical knowledge: the intended purposes of a given genre, the socio-rhetorical context, and dynamics of persuasion.

- Subject-matter knowledge: specialised content knowledge related to the discipline.

Tardy (2009) sees genre knowledge as "an awareness (conscious or unconscious) that can deepen and extend as it is applied in new situations" (p. 22), and the four dimensions of genre knowledge become more integrated as students develop writing expertise. To these four dimensions, Gentil (2011) adds a meta-knowledge of specific genres and of genre as a concept, which develops as writers learn to analyse genre exemplars (see e.g. Cheng, 2007; Kuteeva, 2013; Negretti \& Kuteeva, 2011; Negretti, 2012).

Academic writers display their knowledge of the discipline by, for example, citing key works or appealing to shared knowledge (Hyland, 2000). Disciplinary participation plays a crucial role in developing rhetorical genre knowledge (Tardy, 2009, p. 261) and also results in more routinized composing processes and greater efficiency in approaching writing tasks (Beaufort, 2004). Beaufort's (2004) conceptual model of five knowledge domains (i.e. writing process knowledge, subject matter knowledge, rhetorical knowledge, genre knowledge, and discourse community knowledge) underscores the importance of the discipline: she sees discourse community knowledge as "the broad overarching domain which informs each of the other knowledge domains essential to composing" (p. 141).

Previous research has focused on writers' socialisation processes into a specific discourse community, often resorting to case study methodology due to its suitability in exploring the diversity of writers and writing contexts (Casanave, 2003). The case studies have focused on writers both at the undergraduate level (e.g. Beaufort, 2004) and postgraduate level (e.g. Tardy, 2009). For example, Cheng (e.g. 2006, 2007, 2008, 2011) analyses what multilingual graduate students from different disciplines learn from genre-analysis tasks, and how and to what extent they transfer the genre features they learned from the analysis of model texts into their own writing. His studies have identified the connection between "noticing genre and performing genre" (2007). Kuteeva (2013) examined graduate students' approaches to genre-analysis tasks and observed variation both across and within disciplines.

In this study, we aim to add to this body of research by providing further insights into how students' genre knowledge transfers into different rhetorical strategies across disciplines. Specifically, we focus on the notion of creating a research space (Swales 1990) as it seems to be a rather fundamental requirement for academic writing, and therefore can provide a useful benchmark for comparison. Our study addresses the following research questions:

- How do graduate students from different disciplines use their genre knowledge to create a research space?

- How are their rhetorical and linguistic strategies connected to perceived disciplinary knowledge-making practices? 


\section{Method}

\subsection{Research context}

Our study was carried out at a major Swedish university, in which English is used as an academic language across different disciplines (Bolton \& Kuteeva, 2012). The data were collected in the context of an academic writing course for graduate students. The course encourages students to observe and to discuss variation within the same academic genres across different disciplines, as well as to explore how similar rhetorical purposes, such as creating a research space, can be achieved in different genres. This approach is in line with the one described earlier by Feak and Swales (2011), which in fact represents a common practice of "rhetorical consciousness raising" (Hyland, 2007, p. 13) or fostering genre awareness (Negretti \& Kuteeva, 2011).

Our graduate course runs on a regular basis and enrols approximately 120 students per semester. In line with the ESP genre-based approach (e.g. Paltridge \& Starfield, 2007; Swales, 1990; Swales \& Feak, 2004), its overall aim is to raise students' awareness of the fundamental features of academic genres in general and of their specific disciplinary genres in particular. The course prepares students to write a Master's dissertation and develops a set of genre-analysis skills which will enable students to adapt their writing to specific academic contexts. The main focus is on creating a research space in three academic genres: research articles, dissertations, and research proposals. At the beginning of the course, each student is required to find their own model texts within their discipline: a dissertation and two published articles from prestigious journals in their field. These model texts are used throughout the course as a basis for examining and comparing genre features in two related academic genres: dissertation (a novice researcher genre) and research article (a professional researcher genre). Comparison between the two genres, i.e. a sample dissertation and two research articles within their specific disciplines, helps each student to understand the relationship between the purpose, audience and disciplinary context of their model texts.

In combination with these tasks, students write their own academic text which focuses on the kind of study they aim to carry out for their Master's dissertation. Although the research proposal as a genre is different from dissertations and research articles, and there are further variations between different kinds of research proposals (Feak \& Swales, 2011), we view this genre as belonging to the same network as research articles and dissertations (Tardy, 2009, pp. 13-16). In our case, these were research proposals for Master's dissertations, and their main rhetorical purpose was to "create a research space", to use Swalesian terminology (Swales, 1990). The task prompts which were used to elicit the data for this study can be found in the supplementary materials.

As mentioned in Section 2.2, there are certain similarities in the introductory sections of RAs, dissertations, and research proposals in the sense that their primary goal is to persuade the reader of the importance of the research reported or proposed by the author (Feak and Swales, 2011). Since the requirements for research proposals vary across disciplines and university departments, the students in our mixed-discipline groups were provided with a basic template (title, introduction, literature review, method/theoretical approach, and potential significance; word limit: 3,000 words) but, at the same time, were encouraged to modify this structure and text in 
line with the specific conventions of their disciplines and departments. In the context of our general academic writing course, all students were advised to write their research proposals for a less specialised reader in order to allow for peer review tasks and feedback in class. The writing process took place over the course of five weeks. Students were also frequently asked to reflect on their progress and evaluate their writing, both in collaborative activities and peer reviews and on an individual self-evaluation basis.

\subsection{Data analysis and categorization}

A group of ten graduate students consented to participate in our study and provided us with the material they produced during the course. These students belonged to a variety of disciplinary affiliations, including sciences (physics), social sciences (criminology, political science, education, anthropology, linguistics, Chinese studies), and a wide range of humanities (archaeology, history, literature, cinema studies, history of ideas).

We decided to focus on the Introduction as a "part-genre" (Dudley-Evans, 2000), since this section is present in dissertations, research articles, and research proposals across different disciplines and achieves the key rhetorical function of creating a research space (Swales, 1990). Thus, we collected different types of data relating to the students' approach to writing introductions. Although the different kinds of Introductions analysed and produced by the students followed Swales' (1990) CaRS model to varying degrees, this model nevertheless provided a useful point of departure for comparison between genres and for formulating the students' own ideas about their research projects.

The three types of data from ten consenting study participants included:

1. Students' comparative analysis of the introduction to model texts in their discipline (two research articles and one dissertation) (see Task 1 in supplementary materials);

2. Students' reflections on writing their own introduction during the course (see Task 2 in supplementary materials);

3. Students' introductions to their research proposals (see Task 3 in supplementary materials).

Each type of data was first analysed separately and then in relation to the other types. This comparison of the data was necessary to achieve authenticity or trustworthiness of qualitative research (Guba and Lincoln, 2005): a comprehensive view that can provide explanations about students' genre knowledge and disciplinary knowledge-making practices in the way they read and analyse texts within their field, in their reflections about their own writing, and in the actual texts that they write.

The analysis of the data proceeded in several stages, and was rooted in the general methodological assumptions of grounded theory (Charmaz, 2006): rather than determining apriori categorizations of students' responses, we derived categories from successive stages of close-reading of the data, independent annotation, and constant comparison between our interpretations (Glaser, 1978; Strauss and Corbin, 1998; a map of the coding process can be found in the appendix). Our aim was to draw a connection between students' genre knowledge and disciplinary knowledge-making practices and to identify rhetorical strategies among students in different disciplines. Therefore, we needed to select students that demonstrated awareness of both genre (A) and the discipline (B), the two main categories we derived from the data, as exemplified below:

A. Expressions of genre awareness 
the most important thing to keep in mind was to keep a straight line of thought throughout the introduction. In the introductory section, the reader should ideally be presented with the complete background to the research that was conducted, in a condensed, comprehensive form.

B. Expressions of discipline awareness.

all researchers in the field are usually conducting multi-disciplinary research ... I did bear in mind to keep it general without getting too technical in order to address the broad audience active in the field of Chinese studies.

Five students fulfilled the $\mathrm{A}+\mathrm{B}$ profile. Based on disciplinary affiliation, we report on three students in particular- Chang, Alex, and Helena (fictitious names) who represent the sciences, social sciences, and humanities. In order to provide further evidence of disciplinary rather than individual variation between the three students, we will also include additional excerpts from the other two A+B students - Ingrid and Erik - representing the humanities and social sciences. Background information about the five selected study participants is summarised in Table 1.

\section{Table 1}

Overview of the study participants.

\begin{tabular}{llllll}
\hline Participant & L1 & Age group & Level $^{\mathrm{a}}$ & Discipline (knowledge structure) & Academic languages used \\
\hline Chang & Chinese & $20-25$ & Master (2nd semester) & Biophysics & English, possibly Chinese \\
Alex & Swedish & $30-35$ & Master (2nd semester) & History of ideas & Swedish, French, English \\
Helena & Swedish & $35-40$ & Master (3rd semester) & Chinese studies & Swedish, English, Chinese \\
Ingrid & Swedish & $25-30$ & Master (3rd semester) & Literature (Swedish) & Swedish, English \\
Erik & Swedish & $25-30$ & Master (3rd semester) & Chinese studies & Swedish, English, Chinese \\
\hline
\end{tabular}

a It should be noted that "Level" does not reflect the total number of years students had taken university courses for. At the time of the academic writing course, Alex had been taking university courses for five years, Helena for eight, Ingrid for five, and Erik for four. This information is only partially available for Chang, who started taking courses in conjunction with his Master program the previous year, but who had transferred six Master-level courses from another major University in Sweden, thus amounting to an approximate two to three years of enrolment in University previous to taking our course.

We compared our analysis of the students' reflections with the textual analysis of their introductions to their research proposals, using the CaRS model (Swales, 1990) as analytical framework, to collect evidence about how awareness of disciplinary knowledge-making practices is manifested in different rhetorical and linguistic approaches.

In subsequent rounds of analysis, it emerged that our two main categories were closely related to two dimensions of genre knowledge in Tardy's (2009) model. Thus, expressions of genre awareness (A) concerned primarily the formal dimension, such as the structural elements of genre, whereas discipline awareness (B) involved the rhetorical dimension of genre knowledge, which is related to the intended purposes of genre, its socio-rhetorical context, and dynamics of persuasion. The other two dimensions in Tardy's model - process and subject matter - are less relevant to the purposes and scope of our study. We make use of Tardy's categories, i.e. the formal and rhetorical dimensions of genre knowledge, in our data analysis in the following section which presents our findings in relation to three different disciplinary traditions: the sciences, humanities, and social sciences.

\section{Findings}

Two sets of elicited data - students' analyses of model texts and reflections on their own introductions - provided evidence about these students' knowledge of academic genre conventions within their disciplines, reflected in a variety of remarks about discourse practices, 
rhetorical structure, type of argumentation, use of references, and the way in which research space is created. This understanding of academic genres in their field was often connected to comments about disciplinary knowledge-making practices. The textual data — the students' own introductions - show how their genre knowledge is manifested in different rhetorical strategies to create a research space. The complete set of students' introductions is available in the supplementary online materials.

\subsection{Chang: science (biophysics)}

Chang came to Sweden from China to become a graduate student of biophysics studying through the medium of English. Despite a relatively low proficiency in English, he shows both genre and epistemological awareness.

\subsubsection{Analysis of model texts}

In his comparative analysis of two research articles in his discipline, Chang makes several comments that indicate his genre knowledge, particularly with regard to the formal and rhetorical dimensions (Tardy, 2009) For instance, he defines one of his model texts as "specialized" and aimed at "scientific progress", and therefore concerned with conciseness:

The specialized lab paper which mainly serve to scientific progress, so that the boundary for the paper is within fluency, conciseness, and a well-targeted orientation. (C1)

These comments, corroborated by his comments in class, also suggest an evaluation of the quality of this model text, as indicated above by the positively-connotated "fluency, consistency, and well-targeted". Further, it is possible to hypothesise a perceived connection between these characteristics and the overall purposes of the disciplinary endeavour: twice Chang mentions scientific progress, and in the second case he puts stronger emphasis on scientific progress as obtained by building on previous work (cf. Bernstein, 1999):

[It is quite common to observe] citing and referencing work in the introduction of this kind of academic paper since every scientific progress is made based on the contributions already done by antecedents. (C2)

Chang's evaluation of the other model article appears less positive, and this less positive evaluation seems to be connected to the fact that the text deviates from the scientific purposes of the discipline, and "instead of serving as a purified academic scientific thesis" it "popularizes" scientific concepts. In the following excerpt, the use of "large" and "huge" is juxtaposed with the positively-connotated "fluency, conciseness and well-targeted" descriptives above (C1):

A large amount of words to describe how the research looks in current area and a huge analysis, because this article focuses on popularizing scientific concepts and professional terms instead of serving as a purified academic scientific thesis. (C3)

\subsubsection{Reflection on writing own text}

In his reflection about his own introduction, Chang immediately stresses its function of presenting a "research problem" in a concise and focused manner:

Introduction writing is an art of stating the problem concisely in order to introduce the reader with the research problem ... As for my introduction, the imperative and most difficult aspects lies on an in-depth analysis of the problem concerned instead of a 
prolix description of background information, also it should be well targeted with distinct aims and objectives $(\mathrm{C} 4)$

These comments suggest that Chang is aware that an in-depth analysis of the problem is required, whereas a detailed discussion of the background is not expected in the introductory section. This tension between the amount of attention given to the literature review and a focused research problem indicates Chang's understanding of scientific writing, both with regard to the formal and rhetorical genre knowledge.

Embedded within these reflections on his own writing strategies, Chang also made a couple of comments about "the field" and the writing practices typical of his discipline. Comment C5 below comes as a way of explanation for the strategies described in $\mathrm{C} 4$ and demonstrates Chang's formal genre knowledge:

Providing with a brief history of your topic and explain how it relates to your current research by correct citations. In the field natural science, usually, there is no such independent part as so-called literature review, author demonstrates his or her deliberate academic study and reading directly by citing different papers in the entire article. And Identification of research gap is a very crucial factor for compiling a successful introduction, so does your own 'blue print' regarding on your topic. (C5)

Comment C6 provides another example of Chang's genre knowledge in connection to the natural sciences, both with regard to formal aspects (the discourse of the introduction) and its rhetorical dimension (dynamics of persuasion):

In terms of features of information in the natural sciences, the introduction is supposed to be concise, legible, flexible, specifically oriented, and sufficient matter of facts. Therefore, appropriate reference utilization and pertinent analysis should be organized in an integrated way. (C6)

\subsubsection{The student's text: the introduction}

Chang's rhetorical organization of the introduction to his research proposal seems to align with the type of comments described above. His text follows the CaRS model quite closely: description of the problem and brief review of previous work, establishment of the gap, and explanation of how the study adds to the previous body of knowledge.

Overall, Chang's introduction reads like a problem-solution text. The background is concisely presented through a precise description of his field (nanotechnology as an applied natural science) and the various topics its covers, supported by reference to an eminent physicist:

Nanotechnology has its advents in numerous applications in various fields of science. It is the study of control of matter on an atomic scale. . . . Nanotechnology in its traditional sense, according to a talk given by a physicist named Richard Feynman at an American Physical Society meeting in 1959, means . . . to build a billion tiny factories, models of each other, which are manufacturing simultaneously. The principles of physics, do not speak against the possibility of manoeuvring things atom by atom" (Richard Feynman, 1959). (C7)

Chang's attempt to "re-establish in the eyes of the discourse community the significance of the research field" (Swales, 1990, p. 142) suggests that his perception of the discipline and its practices is manifested in his own writing. 
The introduction then narrows down to the specific problem, and the niche is established primarily by concisely overviewing a phenomenon, rather than reviewing previous research. The gap is indicated by negative or quasi-negative quantifiers (Swales, 1990, p. 155) stressing that so far little research has indicated solutions to the problem, as in this excerpt:

Although the major utilization of nanomaterial (NM) has already come into daily life application, there are relatively few research studies examining the potential environmental and health risks posed by nanoparticles. (C8)

It is noteworthy that despite mentioning "relatively few research studies", C8 contains no references to these studies. This lack of citations indicates a certain tension between Chang's formal knowledge of the genre and its actual enactment of it.

In line with the CaRS model, Chang then outlines the aims of his study and the specific features of the research, a typical example of "occupying the niche" (Swales, 1990, p. 159). Thus, both in his analysis of model texts, his reflection on his own strategies, and in the organization of his text, Chang shows his awareness of disciplinary discourse, in particular with regard to the formal and rhetorical knowledge of the genre (Tardy, 2009). The above-cited comments also reflect what he perceives to be the desirable knowledge-making practices in his discipline. Being a physicist, he underscores the perceived importance of scientific progress by filling gaps and building on the foundations of previous research.

\subsection{Alex and Ingrid: arts and humanities (literary studies and history of ideas)}

Alex was an MA student of the History of Ideas, a discipline that combines the study of literature with the study of philosophy and history. During his studies, which he carried out in Sweden, primarily through the medium of Swedish, Alex frequently read and wrote academic texts in English and other languages. Similarly to Chang, Alex positions himself strongly within a disciplinary identity, but in a different way. Whereas scientific credibility is based on "building on previous research" for Chang, for Alex ethos is established through well-supported, individual claims and original interpretation, as emerges from the overall analysis of his data.

\subsubsection{Analysis of model texts}

In his analysis of introductions, Alex makes several comments about the rhetorical function of his model texts and related disciplinary practices. In this context, like many other Swedish students, Alex is using the word "scientific" (and the related adverb "scientifically") to mean "scholarly" or "academic" as a direct translation of the Swedish "vetenskaplig", whose meaning and usage are broader and can be applied in both the sciences and the humanities. In the excerpt below, he refers to writing in the humanities:

Even though a dissertation produced within a humanistic framework can allow itself to be more of an essay than, for example, a physics dissertation, it still needs to follow certain criteria if it is to be considered scientifically credible. (A1)

Although Alex identifies elements such as problem and the research gap in his texts, he stresses that these elements are integrated into the argumentation, in an "essayistic form". The excerpt below illustrates his formal knowledge of the genre:

[The model dissertation] opens with a short identification of the problem, proceeds by describing the research gap, and then goes on to formulate just how it will fill this gap. The 
article works with these introductory elements as well, but they are less clearly separated. ... thus integrating the "introduction" into the article's essayistic structure. (A2)

Besides specific discipline-related practices, Alex is also aware of the similarities between different academic genres:

They all make use of an academic language, reference other publications, and aim for the scientific ideal of coherence and transparence. (A3)

This awareness of the typical characteristics of academic genres in the humanities is also echoed in the comments of Ingrid, another student of literature. She explains the similarities between the texts in light of disciplinary conventions, calling the style in the humanities "essayistic" (cf. Shaw, 1998). Ingrid also displays formal genre knowledge as she comments on the difference between her model texts as a matter of different academic genres with different purposes:

Although there are similarities, especially when it comes to style, there is one difference that needs to be stressed immediately: Moving Materialities is a dissertation, which "Homeric Nostalgia" isn't. The latter lacks, or has been freed from, some of the criteria that Moving Materialities, being a dissertation, needs to fulfill ... The use of headlines [the student means "subheadings"] ... is one example of such a criterion .... There is also a larger number of concrete formulations. (I1)

\subsubsection{Reflection on writing own text}

Alex's self-reflection on his writing demonstrates his formal and rhetorical knowledge of genre in connection to his perception of the discipline. Specifically, he challenges the idea of a "gap" in the context of how knowledge is created in his field:

I tried to identify some sort of "research gap", although this was difficult because my discipline does not necessarily make use of "research gaps" as starting points for academic texts - at least not in any strict manner. (A4)

Alex's view is not surprising, considering the knowledge-making practices in literary studies. Unlike the sciences, which make use of the gaps to build on the foundations of previous research, the humanities create knowledge through new interpretations of texts (cf. Bernstein, 1999). Alex's approach to writing seems to suggest an awareness of how discursive features connect to different disciplinary knowledge-making practices as embodied in the genre:

I'd like the reader to be interested in what I write, so my texts usually take the form of essays rather than fact-collections (even though the facts and interpretations of course are continually interwoven with the text). (A5)

Ingrid's self-reflection about writing her own introduction mentions the need to adapt the CaRS model to her discipline:

Working out a suitable disposition, I would say, was the most important aspect when writing my introduction. It was crucial to establish a structure which I from now can lean on ... I tried to follow the CARS model, although some adaptations were necessary. Rather than initially describing a "problem/difficulty/situation," I am introducing a theme. (I2) 


\subsubsection{The students' texts: the introduction}

Alex's own introduction reflects an understanding of the rhetorical and knowledge-making practices adopted in literary studies. Some elements of the CaRS model can be traced, especially in the initial paragraph, but overall the introduction reflects his perceived need to create something in harmony with the purposes and practices of his field. Thus, his introduction is focused on presenting an argument and explaining its relevance through a series of interconnected paragraphs increasingly narrowing the focus of the discussion to elaborate on the main claim, in a format that — as Alex himself put it — could be called "essayistic" (cf. Shaw, 1998).

The first paragraph immediately introduces the specific topic and establishes significance by using language that conveys stance (Swales, 1990, pp. 148-154; Swales \& Feak, 2004, p. 242, 284). Notice, for instance, the juxtaposition of adjectives, "important" versus "obscure" and "huge" versus "unknown", which immediately gives a sense of Alex's positioning:

Georges Bataille (1897-1962) is an important but rather obscure figure in French intellectual history. His influence upon post-war continental philosophy has been huge, despite the fact that he, by the time of his death, was more or less unknown. (A6)

After a few brief generalizations, the last sentence of the first paragraph establishes a niche by pointing out the prevalent view in the specific disciplinary community which Alex belongs to:

The novels L'Histoire de l'CEil and Le bleu du ciel have often been categorized as "surrealistic" and/or "erotic" literature. Most Swedish research on Bataille has been centered around these works. (A7)

Then, in the first sentence of the following paragraph, rather than indicating a "gap" or a "problem", Alex presents a counter-claim to the prevalent view (Move 2) and occupies the niche (Move 3), positioning his work in a broader perspective:

However, Bataille's fictional works are in the background of this study, which investigates how different political attempts during an increasingly politicized era - the 1930's culminated in a project best described as anti-political. (A8)

The rest of the introduction develops this argument in an increasingly more specific way. Through several coherent paragraphs, the main claim is supported by a detailed overview of the historical and political background, the connections between politics, historical events and philosophy in Bataille's work in general and in relation to the specific project which is the focus of Alex's research. After this extensive overview, the argument is re-proposed and rephrased, and the niche occupied. Notice how evaluative language is used to indicate Alex's personal stance and to suggest the significance of the topic of interest:

Acéphale created an understanding and a community that best can be described as a "religion without God". What interests me in this apparently paradoxical turn is mainly the question of just how much it was a break with politics - and if it was, how this break was produced by politics itself - but also how well it managed to carry out the radical visions of desobjectivation and transgression that Bataille had developed since at least one decade. (A9)

Similarly, Ingrid creates a niche by gradually introducing a theme, a unique idea and approach to interpretation, rather than delineating a gap in previous research. The theme 
is proposed at the very beginning of the text, in general terms, with thought-provoking quotes:

This thesis deals with the finitude of the text. The point of departure is constituted by Martin Hägglund's understanding of Derrida's concept "différance," namely, that "there cannot even in principle be anything that is exempt from temporal finitude." (I3)

The theme is proposed successively in a way that leads the reader to understand it almost inductively rather than explicitly, despite frequent statements of aim (possibly with the purpose of enhancing clarity):

By scrutinizing some commentaries on Heraclitus's fragments, I argue that the text, as everything else, eventually will fall apart ... I seek to demonstrate how time works upon the poem. Every interpretation, I claim, needs a perspective from which the destruction of the text can be studied. (I4)

Thus, both Alex and Ingrid display their formal and rhetorical knowledge in connection to perceived disciplinary practices in literary studies, where language plays a vital role in creating knowledge through interpretation based on the researcher's individual perspective. Compared to Chang's introduction, there are no clear gaps to be filled, and the research niche is created through personal argumentation.

\subsection{Helena and Erik: social sciences and humanities (Chinese studies/psychology/sociology)}

Helena's case illustrates how students who carry out interdisciplinary research develop a sort of "metaknowledge of genre" (Gentil, 2011), as a result of their need to address different audiences. The picture is further complicated by the fact that Helena belongs to what Erik, another student in the same field, defined as a "pseudo-discipline", meaning that Chinese studies is a broad interdisciplinary field that often borrows theories and approaches from other more demarcated disciplines (cf. Trowler 2014). Helena's interdisciplinary focus calls into play theories of psychology, a field which can be regarded as a typical example of "warring triangles" (Wignell, 2007). This situation creates challenges and forces Helena to closely examine her rhetorical approach and to adapt it to different discursive requirements.

\subsubsection{Analysis of model texts}

Helena's analyses of model texts suggest formal and rhetorical knowledge of the aspects that distinguish academic genres within her field:

My sample thesis is a rather unique piece of work, even within the field of sinology. (H1)

She also shows awareness that academic genres represent a way to construct knowledge. Her critique below is not aimed at the rhetorical effectiveness of the text, but at the fact that the text seems to lack this fundamental epistemological feature:

Very clear and easy to follow, but the author never really specifies what he is hoping to add to the body of knowledge, even the sole purpose of his research. (H2)

In contrast, her critique of one of the model articles is more positive, as it "clearly stakes out the importance and the focus" (H3) and illustrates the gap in the field. 
Helena's observations have many points in common with those made by Erik, another A+B student included in the study, also enrolled in an MA program in Chinese Studies. This student displays his formal knowledge of two genres (the dissertation and the article):

Obviously, there were bound to be some fundamental differences between the dissertation and the articles. For starters the articles weren't concerned with methodology ... Also, they tended to be structured rather loosely, a more personal, free-form approach. (E1)

Although Erik does not make any specific comments about disciplinary discourse or genre prototypicality, he also seems to be able to analyse the texts rather closely in terms of rhetorical requirements and purpose, as shown in his comments about the differences between the articles:

It is interesting to comment on the lengths of the different introductory sections ... It could be argued that the reason for this would be that this was warranted in order to provide the reader with a deeper understanding of the background facts ... a theory that to a greater extent requires a thorough presentation of the subject before attempting to discuss it. (E2)

\subsubsection{Reflection on writing own text}

In her reflection on writing an introduction to her research proposal, Helena shows her formal and rhetorical genre knowledge in connection to how her writing choices conform to (or deviate from) the disciplinary genre conventions. She makes further comments indicating a conscious effort to balance disciplinary discourse and the contextual requirements of the assignment, which was aimed at a non-specialised audience:

Works of the sinological discipline really need lots of footnotes, in order to be appreciated and understood by an average academic audience. (H4)

The following comment also suggests the student's understanding of the socio-rhetorical context in her discipline:

I was really trying to write as if I was addressing a reader with no foreknowledge of Chinese culture, whatsoever. I found that very difficult, though, as I am touching on a subject that is very uniquely Chinese. (H5)

In relation to the above issues, Helena critically reflects on the challenges posed by the task, and the following expressions show her effort to adapt the genre to the new situation:

Some basic concepts have to be explained already in the introduction. So, although one of the important aspects was to keep the introduction concise, I have to make some further effort in explaining the potential significance of my study. (H6)

Similarly, Erik comments about the need to be exhaustive but clear in the introduction to the research proposal, in order to meet the needs of a "broad audience":

In the introductory section, the reader should ideally be presented with the complete background to the research ... technical details should be left to later chapters: it is important that the introduction makes for a good read. (E3)

He, therefore, made conscious efforts to adapt the text to an audience not necessarily versed in Chinese culture, in order to achieve clarity and efficacy of argumentation:

I managed to establish coherency in the text by moving from the general to the specific ... 
I actually didn't have to concern myself a lot with adapting the introduction to suit disciplinary standards since my discipline (Chinese studies) basically is a pseudo-discipline. Almost all researchers in the field are usually conducting multi-disciplinary research in areas ... keep it general without getting too technical in order to address the broad audience active in the field of Chinese studies. (E4)

\subsubsection{The students' texts: the introduction}

Helena's formal and rhetorical knowledge of the genre is evident in her way of organizing the introduction to her research proposal and the way she establishes a niche for her research. In the first place, to create a fluid argumentative structure, Helena opts for writing a long introduction which includes the literature review, and which therefore presents several instances of what Swales (1990) calls "cyclicity" (p. 158) in establishing a niche. The introduction/literature review is organized according to different themes or concepts, so that the space for the research is gradually cleared through recurring statements indicating a niche or gap.

Her introduction begins with a couple of paragraphs establishing territory by providing a detailed background of the historical/cultural phenomenon, with an example offering further clarification. Then, Helena establishes a niche across several paragraphs, through a review of literature from different disciplinary fields, thereby "making knowledge" across different disciplines. Gap statements are made using different rhetorical strategies, and they are followed by a variety of statements about how the niche will be occupied.

For instance, in her third paragraph, Helena uses counter-claiming to indicate the gap:

$\mathrm{Fu}$ solely discusses the social realist films of director Long Gang. These films are by all means worth studying, but as can be seen from the aforementioned example, wuxia movies can be far more daring in their representations of moral subversion. (H7)

She then proceeds to occupy the niche by presenting her argument and her aims:

Therefore, I would argue that studies about the dynamic flux between popular culture and sociocultural structures in 60's Hong Kong should also embrace the significance of wuxia movies. By analyzing a wuxia product, released in the local dialect (粤话), we shall argue for this significance. We will examine how the generation gap is represented in these movies with insights made from cross-cultural studies of psychotherapy. (H8)

This general statement of the niche is followed by a detailed literature review framed by several gap statements:

The cinema of Hong Kong has been rather neglected as a field of study, at least until the late 1990s. (H9)

This kind of neglect, however, still plagues the wuxia film as an isolated genre. Although arguably the oldest genre still popular with Chinese audiences to this very day, its history has hardly been told at all. (H10)

Relatively few scholars or clinicians have examined culture and psychotherapy from theoretical or philosophical levels, beyond technical or practical dimensions. (H11) 
Thus, in these three gap statements, Helena indicates different foci and angles of her research, including the topic ("the cinema of Hong Kong" (H9) and "the wuxia film" (H10)) and the ontological and epistemological aspects ("culture and psychotherapy", "theoretical or philosophical levels" (H11)).

Thus, Helena's introduction contains all the rhetorical moves of the CaRS model but is organized in an order dictated by the necessity to cover cross-disciplinary topics, therefore establishing a personal line of argumentation.

A similar approach, with conscious effort to meet the rhetorical requirements of addressing a broad audience across two disciplines, sinology and ethnomusicology, is also reflected in Erik's introduction: a well-delimited, coherent section clearly stakes out the niche in a way that is comprehensible by a non-expert academic audience. Using the CaRS as a general outline, Erik describes a cultural phenomenon both historically and in current terms. His text increasingly zooms in to the "problem" and concludes by simultaneously indicating gaps and posing the research questions that he aims to answer:

The purpose of this study is to examine the relationship between the CCP and popular music, more specifically the independent music scene in Beijing. To what extent is this music political? What regulations are imposed on the artists? How do these artists respond to censorship? In other words, how "independent" is this music? These questions address previously unexplored issues in the fields of sinology and ethnomusicology. (E5)

The rhetorical features of Helena's and Erik's introductions manifest tensions resulting from their need to address interdisciplinary audiences and can be connected to their perception of disciplinary practices in Chinese studies.

\section{Discussion and conclusion}

Our study aimed to show the connection between genre knowledge and perceived disciplinary knowledge-making practices. Our research questions were: How do graduate students from different disciplines use their genre knowledge to create a research space? How are their rhetorical and linguistic strategies connected to perceived disciplinary knowledge-making practices?

In answer to the first question, the focal students in our study create a research space in different ways. For example, the link between the discipline and genre knowledge is found in the way that students reflect on, and make use of, the different steps of the CaRS model (Swales, 1990). Chang emphasises the importance of scientific progress by filling gaps and building on the foundations of previous research. His own introduction contains a clear gap statement (C8), followed by a statement of aims. "Conciseness" and "scientific progress" were terms that seem to recur quite often in Chang's words and reflect his perceptions of knowledge-making practices in his discipline. For Alex, on the other hand, research space is created through well-supported, individual claims and original interpretation (A2). Alex's own introduction is focused on presenting an argument through a counter-claim (A8) and explaining its relevance in an "essayistic" style. Evaluative language is used to indicate stance and underscore the significance of the topic (A9). Both Alex and Ingrid represent literary studies in which language plays a vital role in creating knowledge through interpretation based on the researcher's individual perspective. There are no clear gaps to be filled, and the research niche is created through personal argumentation. Finally, the social scientist Helena creates a research space by opting for 
a long introduction which includes the literature review and which presents several instances of what Swales (1990) calls "cyclicity" (p. 158) in establishing a niche, due to an interdisciplinary dimension of her research. Her own introduction/literature review is organized according to different themes or concepts, so that the research space is gradually cleared through recurring statements indicating a niche or gap (H7, H9, H10, H11). Overall, the rhetorical features of Helena's and Erik's introductions reflect their perception of Chinese studies as a field and its multiple research perspectives.

Moving on to the second question, the linguistic and rhetorical strategies used by the science writer Chang were connected to ideals of clarity, conciseness, and scientific progress (C2), (C4), and (C5). On the other hand, the student-writers operating within a broad humanistic paradigm, adopted strategies that aimed at constructing knowledge inductively, foregrounding their authorial persona (A9), (I4), and by interweaving ideas and justifications within an unraveling argument (A2), (A4), (A5) and the introduction of a theme (I2). Finally, balancing practices of knowledge construction rooted in different disciplines, the social scientists created a research space cyclically, by making it explicit how their work added to different bodies of knowledge $(\mathrm{H} 2)$, and by deploying an array of rhetorical tools — organization of the argument (E2), explicitness in the description of significance (H6) and the adoption of concise language - to enhance the value of their word to diverse audiences (H4), (E3). These students seemed aware of how knowledge is constructed through language in their areas of work, and our study illustrates how differences in this awareness were intentionally transposed into different approaches to writing.

The cases described above show that the connection between genre knowledge and knowledgemaking practices is manifested in the particular way these graduate students analyse their model texts, reflect on their own writing, and use rhetorical features to create a research space. This finding underscores the importance of the discipline in the conceptualization of genre knowledge. Tardy's (2009) model provides a comprehensive overview of four different dimensions, and disciplinary practices play an important role in contributing to students' formal and rhetorical genre knowledge, as discussed in the previous section. Our findings also seem to be in line with Beaufort's (2004) conceptual model which views discourse community knowledge as the overarching domain all over other knowledge domains in writing expertise. Although Beaufort's model is based on research into the disciplinary writing practices of L1 students, it can be applied to L2 contexts. This interplay between genre and the discipline becomes particularly interesting when the knowledge-making practices associated with L1 and L2 are not the same, as would be the case in some areas of the humanities and social sciences (cf. Trowler, 2014).

According to Gentil (2011, p. 20), it seems "likely that multilingual genre learning should promote genre awareness, rhetorical flexibility, and audience sensitivity, although this remains an empirical question". Gentil's case illustrates a relative ease of genre knowledge transfer between L1 and L2. Swales (2011) attributes this finding to the fact that Gentil's case study focuses on a professional linguist for whom negotiation between L1 and L2 genres may be easier, compared to scientists who often possess relatively inferior L2 writing skills, and "this kind of negotiation may be easier for language specialists than for economists or plant pathologists" (Swales, 2011, p. 83). Our study suggests that it is not only scientists who face such challenges, and that academic writing in English as an additional language poses different kinds of challenges across disciplines. In the natural sciences, language per se is less important when it comes to knowledge construction. That is partly the reason why some relatively low L2 
proficiency students, such as Chang in our study, can possess both formal and rhetorical knowledge of genres in connection to perceived disciplinary practices. Obviously, low L2 proficiency will affect the quality of writing at the micro-level but language as such (whether L1 or L2 or other) will not play a key role in communicating scientific findings since knowledge is built on the foundations of previous research (cf. Bernstein, 1999). In the humanities, language plays a crucial role in knowledge construction, which is manifested in disciplinary discourses and academic genres both at the micro and macro levels (i.e. the structure of the introduction and the lexicogrammatical features used to position research in the field). Thus, compared to the sciences, the disciplines dealing with interpretations require a higher degree of genre awareness and rhetorical flexibility, particularly in multilingual writing contexts. Our study suggests that developing genre knowledge in L2 can be more challenging for L2 writers in the humanities and social sciences.

Our findings have implications for EAP pedagogy, as universities all over the globe are dealing with heterogeneous student populations and are beginning to offer English-medium instruction and academic writing courses to students of the humanities and social sciences. Research has shown that the goals of writing instruction are affected by both local and global requirements (Breeze 2012, p. 30), often resulting in the development of new, hybrid genres. For example, writing assignments at universities in different parts of the world require mastery of a large volume of information from different academic sources, a good knowledge of subject-specific terminology, use of appropriate style guidelines, and so forth. Some research-based textbooks (e.g. Feak \& Swales, 2011; Swales and Feak, 2012) provide a solid basis for teaching academic writing to graduate students. However, these textbooks do not entirely reflect the reality of universities where multilingual students do not always write in the same genres as those studying in the US. The local languages and cultures have an impact on disciplinary practices (cf. Trowler 2014) and associated academic genres. Hybrid genres often develop as a result of using English for traditional writing assignments required by different European universities, when some aspects of English academic writing are blended with local rhetorical traditions (see Breeze 2012).

Our study concerns a detailed qualitative analysis of student writing in English as additional language, drawing on three different data sets. The focal participants had different educational and linguistic backgrounds and, with the exception of Chang, regularly used languages other than English in their research. Due to a limited number of participants and specific sociogeographical context, our findings cannot be generalized. However, we hope to have raised a number of important issues which require further research. For example, to strengthen the pedagogical potential of our findings, further studies could among other things explore the qualitative changes in students' genre knowledge - and specifically of the need to create a research gap - before and after a genre-based course, and possibly triangulate the coherence of these perceptions with the actual, contextual requirements set by departments and supervisors. Academic genres embody and express disciplinary knowledge-making practices, and understanding this connection is important for graduate students if they wish to successfully appropriate genre features in their own writing. 


\section{References}

Beaufort, A. (1999). Writing in the real world: Making the transition from school to work. New York: Teachers College Press.

Beaufort, A. (2004). Developmental gains of a history major: A case for building a theory of disciplinary writing expertise. Research in the Teaching of English, 39(2), 136-185.

Becher, T. (1987). Disciplinary discourse. Studies in Higher Education, 12(3), 261-274.

Becher, T. (1989) Academic tribes and territories: Intellectual enquiry and the cultures of disciplines. Milton Keynes: Open University Press.

Becher, T. \& Trowler, P. (2001). Academic tribes and territories. Buckingham: Open University Press.

Bernstein, B. (1999). Vertical and horizontal discourse: An essay. British Journal of Sociology of Education, 20(2), 157-173.

Bolton, K. \& Kuteeva, M. (2012). English as an academic language at a Swedish university: parallel language use and the "threat" of English. Journal of Multilingual and Multicultural Development, $33,429-447$.

Bondi, M. (2007). Authority and expert voices in the discourse of history. In K. Floettum (ed.), Language and discipline perspectives on academic discourse, pp. 66-88. Newcastle: Cambridge Scholars Press.

Breeze, R. (2012). Rethinking academic writing pedagogy for the European university. Amsterdam/New York: Rodopi.

Casanave, C. (2003). Looking ahead to more socio-politically-oriented study research in L2 writing scholarship. Journal of Second Language Writing, 12, 85-102.

Charmaz, K. (2006). Constructing grounded theory. London: Sage.

Cheng, A. (2006). Analyzing and enacting academic criticism: The case of a graduate learner of academic writing. Journal of Second Language Writing, 15, 279-306.

Cheng, A. (2007). Transferring generic features and recontextualizing genre awareness: Understanding writing performance in the ESP genre-based literacy framework. English for Specific Purposes, 26, 287-307.

Cheng, A. (2008). Individualized engagement with genre in academic literacy tasks. English for Specific Purposes, 27, 387-411.

Cheng, A. (2011). Language features as the pathways to genre: Students' attention to non-prototypical features and its implications. Journal of Second Language Writing, 20, 69-82

Christie, F., \& K. Maton (2011). Disciplinarity: Functional linguistic and sociological perspectives. London: Continuum.

Dudley-Evans, T. (2000). Genre analysis: A key to a theory of ESP? Ibérica, 2, 3-11.

Feak, C.B. and J.M. Swales (2011). Creating contexts: Writing introductions across genres. Ann Arbor: University of Michigan Press. 
Flowerdew, J. (2011). Reconciling contrasting approaches to genre analysis: The whole can equal more than the sum of its parts. In D. Belcher, A. Johns, and B. Paltridge (Eds), New directions in English for Specific Purposes research, pp. 119-144. Ann Arbor: University of Michigal Press.

Gentil, G. (2011). A biliteracy agenda for genre research. Journal of Second Language Writing, 20(1), 6-23.

Glaser, B. (1978). Theoretical sensitivity: Advances in the methodology of grounded theory. Mill Valley, CA: Sociology Press.

Guba, E., \& Lincoln, Y. (2005). Paradigmatic controversies, contradictions, and emerging confluences. In N. K. Denzin \& Y. S. Lincoln (Eds.), Handbook of qualitative research, (pp. 191-215). Thousand Oaks, CA: Sage.

Hewings, A. \& Hewings, M. (2001). Anticipatory 'it' in academic writing: An indicator of disciplinary difference and developing disciplinary knowledge. In M. Hewings (ed.), Academic writing in context; Implications and Applications, pp. 119-214. Birmingham: University of Birmingham Press.

Hood, S. (2011). Writing discipline: Comparing inscriptions of knowledge and knowers in academic writing. In F. Christie \& K. Maton (Eds.), Disciplinarity. pp. 106-128. London: Continuum.

Huckin, T. (2001). Abstracting from abstracts. In M. Hewings (Ed.), Academic writing in context: Implications and applications, pp. 93-103. Birmingham: University of Birmingham Press.

Hyland, K. (1999). Academic attribution: Citation and the construction of disciplinary knowledge. Applied Linguistics, 20, 341-367.

Hyland, K. (2000). Disciplinary discourses: Social interactions in academic writing. Ann Arbor: University of Michigan Press.

Hyland, K. (2004a). Genre and second language writing. Ann Arbor: University of Michigan Press.

Hyland, K. (2004b). Disciplinary interactions: Metadiscourse in L2 postgraduate writing. Journal of Second Language Writing, 13, 133-151.

Hyland, K. (2005). Metadiscourse: Exploring interaction in writing. London: Continuum.

Hyland, K. (2007). Genre pedagogy: Language, literacy, and L2 writing instruction. Journal of Second Language Writing, 16(3), 148-164.

Hyland, K. (2008). As can be seen: Lexical bundles and disciplinary variation. English for Specific Purposes, 27(1), 4-21.

Johns, A. (1997). Text, role, and context: Developing academic literacies. Cambridge: Cambridge University Press.

Johns, A. M. (2002). Genre in the classroom: Multiple perspectives. Mahwah, NJ: Lawrence Erlbaum.

Kuteeva, M. (2013). Graduate learners' approaches to genre-analysis tasks: Variations across and within four disciplines. English for Specific Purposes, 32(2), 84-96.,

Kuteeva, M. \& McGrath, L. (2015). The theoretical research article as a reflection of disciplinary practices: The case of pure mathematics. Applied Linguistics, 36(2), 215-235. 
Lin, L., \& Evans, S. (2012). Structural patterns in empirical research articles: A cross disciplinary study. English for specific Purposes, 31(3), 150-160.

Martin, J. R. (2011). Bridging troubled waters: Interdisciplinarity and what makes it stick. In F. Christie \& K. Maton (Eds.), Disciplinarity. pp. 35-61. London: Continuum.

Martin, J., K. Maton, \& Matruglio, E. (2010). Historical cosmologies: Epistemology and axiology in Australian secondary school history discourse. Signos, 43, 433-463.

McGrath, L. and Kuteeva, M. (2012). Stance and engagement in pure mathematics research articles: Linking discourse features to disciplinary practices. English for Specific Purposes, 31(3), 161-173.

Negretti, R. \& Kuteeva, M. (2011). Fostering metacognitive genre awareness in L2 academic reading and writing: a case study of pre-service English teachers. Journal of Second Language Writing, 20(2), 95-110.

Negretti, R. (2012). Metacognition in student academic writing: A longitudinal study of metacognitive awareness and its relation to task perception and evaluation of performance. Written Communication, 29(2), 142-179.

Ozturk, I. (2007). The textual organization of research article introductions in applied linguistics: Variability within a single discipline. English for Specific Purposes, 26(1), 25-38.

Paltridge, B. \& Starfield, S. (2007). Thesis and dissertation writing in a second language: A handbook for supervisors. London: Routledge.

Samraj, B. (2002). Introductions in research articles: Variations across disciplines. English for Specific Purposes, 21(1), 1-17.

Shaw, P. (1998) Patterns of argument in published articles in literary studies. In Lundquist, L., Picht, H. and Qvistgaard, J. (Eds), LSP Identity and Interface. Research, Knowledge and Society Proceedings of XI LSP Symposium Copenhagen, August 1997. Copenhagen: Copenhagen Business School.

Strauss, A. \& Corbin, J. (1998). Basics of qualitative research: Techniques and procedures for developing grounded theory. Newbury Park: Sage Publications.

Swales, J. M. (1981). Aspects of article introductions. Birmingham: University of Aston.

Swales, J. M. (1990). Genre analysis: English in academic and research settings. Cambridge, UK: Cambridge University Press.

Swales, J. M., \& Feak, C. B. (2004). Academic writing for graduate students: Essential tasks and skills (2nd ed.). Ann Arbor, MI: University of Michigan Press.

Swales, J. M., \& Feak, C. B. (2012). Academic writing for graduate students: Essential tasks and skills (3rd ed.). Ann Arbor, MI: University of Michigan Press.

Swales, J. M. (2004). Research genres: Explorations and applications. Cambridge: Cambridge University Press.

Swales, J. M. (2011). Coda: Reflections on the future of genre and L2 writing. Journal of Second Language Writing, 20(1), 83-85.

Tardy, C. (2009). Building genre knowledge. West Lafayette: Parlor Press. 
Trowler, P. (2014). Depicting and research disciplines: Strong and moderate essentialist approaches. Studies in Higher Education. 39(10), 1720-1731.

Wignell, P. (2007). Vertical and horizontal discourse and the social sciences. In F. Christie and J. R. Martin (Eds.), Language, knowledge and pedagogy: Functional linguistic and sociological perspectives, pp. 184-204. London: Cassell.

Yang, R. \& Allison, D. (2004). Research articles in applied linguistics: Studies from a functional perspective. English for Specific Purposes, 23, 264-279. 


\section{Appendix. Coding and analysis process}

\section{Type of data} Students' analyses of research articles' introductions

\section{Open coding} - Identify statements in which to rhetorical aspects of academic writing $\rightarrow$ category A

- Identify statements in which students make explicit reference to disciplinary expectations in terms of writing $\rightarrow$ category B

Self-reflections on writing own introduction

Self-reflections on writing Same as above research proposal

Same as above

e
students make explicit reference
Coding stages $*$

\section{Axial coding}

- $\begin{aligned} & \text { Compare our coding and } \\ & \text { examples under category } \\ & \text { A and B }\end{aligned}$
- $\begin{aligned} & \text { Identify students who } \\ & \text { present examples of both } \\ & \text { categories. }\end{aligned}$

Selective coding data source, for each

- Select/verify examples

S

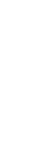

- Create a commentary for each student across data sources with examples of categories A and B category A and category B for each student for each student

Axial coding

Cross-compare the data

Compare identified

categories in each student with Tardy's (2009) model: Category A: mainly formal knowledge of genre Category B: mainly sociorhetorical context of genre

- Revise our interpretive account in the text.

* Based on Strauss, A. \& Corbin, J. (1990). Basics of Qualitative Research: Grounded Theory Procedures and Techniques. Newbury Park, CA: Sage Publications. 